\title{
MicroRNA-610 is downregulated in glioma cells, and inhibits proliferation and motility by directly targeting MDM2
}

\author{
YU YAN, YONG PENG, YANGZHU OU and YUGANG JIANG
}

Department of Neurosurgery, The Second Xiangya Hospital, Central South University, Changsha, Hunan 410011, P.R. China

Received June 25, 2015; Accepted May 3, 2016

DOI: $10.3892 / \mathrm{mmr} .2016 .5559$

\begin{abstract}
The expression of microRNA (miR)-610 has previously been reported to be downregulated in gastric cancer and hepatocellular carcinoma. However, miR-610 has yet to be investigated in human glioma. In the present study, miR-610 expression was analyzed by reverse transcription-quantitative polymerase chain reaction. Post-transfection with miR-610 mimics and inhibitors, MTT assay, cell migration and invasion assays, western blot analysis and a luciferase assay were performed in glioma cell lines. The results demonstrated that miR-610 was downregulated in glioma tissues compared with their normal adjacent tissues and normal brain tissues $(\mathrm{P}<0.05)$. The reduced expression levels of miR-610 were associated with World Health Organization grade and the Karnofsky performance status of patients with glioma. Furthermore, the present study revealed that miR-610 inhibited cell growth, migration and invasion in glioma cells. To the best of our knowledge, the present study is the first to provide evidence suggesting that miR-610 directly targets MDM2 proto-oncogene E3 ubiquitin protein ligase to function as a tumor suppressor in glioma. These results indicate that miR-610 may be investigated as a target for therapeutic drugs designed to treat glioma.
\end{abstract}

\section{Introduction}

Human glioma, which is the most common and fatal primary brain tumor, originates from glial cells and accounts for $70 \%$ of malignant primary brain tumors (1). In the United States, the estimated incidence rate of glioma is 20,000 new cases per year (2). Glioma is classified into three major histological groups, as follows: Well-differentiated low grade diffuse astrocytoma; anaplastic astrocytoma; and glioblastoma

Correspondence to: Professor Yugang Jiang, Department of Neurosurgery, The Second Xiangya Hospital, Central South University, 139 Middle Renmin Road, Changsha, Hunan 410011, P.R. China

E-mail: yugangjiang1025@163.com

Key words: glioma, MDM2 proto-oncogene E3 ubiquitin protein ligase, microRNA-610, motility multiforme, according to the 2007 World Heath Organization (WHO) classification (3). Despite progress being made in improving the treatment of glioma, including the use of aggressive surgery combined with chemotherapy, radiotherapy and biological therapy, the final prognosis of glioma remains extremely poor because the tumors are highly proliferative and invasive $(4,5)$. The average 5-year survival rate of glioma is $4-5 \%$ and mean survival time following diagnosis is $12-15$ months $(6,7)$. Therefore, it is crucial to explore the molecular mechanisms underlying glioma, in order to improve the prognosis for patients with glioma.

MicroRNAs (miRNAs, miR) have been demonstrated to alter the expression of genes involved in gliomagenesis (8). miRNAs are a group of endogenous, small non-coding RNAs 22-25 nucleotides in length, which are derived from pri- and pre-miRNAs (9). miRNAs regulate the expression of their target mRNAs through partial complementarity to seed sequences in the 3'-untranslated region (UTR) of the target gene, resulting in translational suppression or mRNA cleavage (10). Notably, studies have demonstrated that miRNAs regulate several important normal biological processes and pathological processes, including cell proliferation, apoptosis, differentiation, metabolism and metastasis $(11,12)$. Calin et al $(13)$ demonstrated that $~ 50 \%$ of miRNAs are located at fragile sites and cancer susceptibility locations, thus indicating the potential functions of miRNAs in tumor formation. Furthermore, it has been suggested that the expression of miRNAs are often down- or upregulated in numerous types of cancer, and can function as tumor suppressors or oncogenes in various tumors (14), including glioma. Therefore, further exploration of the functions and target mRNAs of miRNAs may provide insight into the mechanisms of glioma development and progression. It has also been suggested that miRNAs may be targets for cancer therapy.

The expression levels of miR-610 were previously reported to be downregulated in gastric cancer and hepatocellular carcinoma $(15,16)$. However, to the best of our knowledge, there have been no studies of miR-610 in glioma. In the present study, the expression and function of miR-610 in glioma was examined. The results of the present study demonstrated that miR-610 was downregulated in human glioma tissues compared with their normal adjacent tissues (NATs) and normal brain tissues. In addition, the low expression levels of miR-610 were associated with WHO grade and the 
Karnofsky performance status (KPS) of patients with glioma. Furthermore, miR-610 suppressed cell proliferation, migration and invasion by directly targeting MDM2 proto-oncogene E3 ubiquitin protein ligase (MDM2). The findings of the present study have therapeutic implications and may be exploited for the treatment of glioma.

\section{Materials and methods}

Clinical specimens. The tumor specimens used in the present study were obtained from patients that had undergone surgery at the Second Xiangya Hospital, Central South University (Changsha, China). Normal brain tissues $(n=5)$ used in the present study were obtained from patients with traumatic brain injury requiring a partial resection of brain tissues to decrease the intracranial pressure. Informed consent was obtained from all patients. Of the samples from patients with glioma, 29 cases were low-grade (WHO I and WHO II) and 32 cases were high-grade (WHO III and WHO IV). Tissues were snap-frozen in liquid nitrogen and were stored at $-80^{\circ} \mathrm{C}$. This study was approved by the institutional review board of the Second Xiangya Hospital.

Cell lines and cell transfection. The human U251 and U87 glioma cell lines were purchased from the Shanghai Institute of Biochemistry and Cell Biology (Shanghai, China). The cells were cultured in Dulbecco's modified Eagle's medium (Gibco; Thermo Fisher Scientific, Inc., Waltham, MA, USA) supplemented with $10 \%$ v/v fetal bovine serum (FBS; Gibco; Thermo Fisher Scientific, Inc.) at $37^{\circ} \mathrm{C}$ in a cell incubator containing $5 \% \mathrm{CO}_{2}$.

Mature miR-610 mimics, miRNA mimics negative control (NC), miR-610 inhibitor, miRNA mimics negative control inhibitor (NC inhibitor) and the luciferase reporter plasmid were designed, synthesized and validated by GeneChem Co., Ltd. (Shanghai, China). PGL3-MDM2-3'UTR Wt and PGL3-MDM2-3'UTR Mut luciferase reporter plasmid were designed, synthesized and confirmed by Shanghai GenePharma Co., Ltd., (Shanghai, China). Cell transfection and co-transfection was conducted using Lipofectamine 2000 (Invitrogen; Thermo Fisher Scientific, Inc.), according to the manufacturer's protocol. The pcDNA3.1-MDM2 plasmid was synthesized by GeneChem Co., Ltd., and MDM2 cDNA was cloned into a pcDNA plasmid purchased from GeneChem Co., Ltd. A total of $24 \mathrm{~h}$ after co-transfection, the cells were used for rescue experiments.

RNA extraction and reverse transcription-quantitative polymerase chain reaction ( $R T-q P C R)$. Total RNA was isolated from homogenized tissues and cells using TRIzol ${ }^{\circledR}$ reagent (Invitrogen; Thermo Fisher Scientific, Inc.) according to the manufacturer's protocol. RT was conducted using Moloney Murine Leukemia Virus Reverse Transcription system (Promega Corporation, Madison, WI, USA). The reverse transcription was performed in a $25 \mu \mathrm{l}$ reaction volume. The temperature protocol was as follows: $95^{\circ} \mathrm{C}$ for $2 \mathrm{~min} ; 20$ cycles of $94^{\circ} \mathrm{C}$ for $1 \mathrm{~min}, 55^{\circ} \mathrm{C}$ for $1 \mathrm{~min}$ and $72^{\circ} \mathrm{C}$ for $2 \mathrm{~min}$; and $72^{\circ} \mathrm{C}$ for $5 \mathrm{~min}$. RT-qPCR was performed using a SYBR Premix Ex Taq kit (Takara Biotechnology Co., Ltd., Dalian, China) and Applied Biosystems 7500 Real-Time PCR system (Thermo
Fisher Scientific, Inc.) according to the manufacturers' protocols. SYBR Green PCR master mix (Takara Biotechnology Co., Ltd.) was used to measure the mRNA expression levels of MDM2. The $20 \mu \mathrm{l}$ reaction system contained $10 \mu \mathrm{l}$ SYBR Green I mix, $2 \mu 1$ forward primer, $2 \mu 1$ reverse primer and $4 \mu 1$ double distilled water. The cycling conditions were as follows: $95^{\circ} \mathrm{C}$ for $10 \mathrm{~min} ; 40$ cycles at $95^{\circ} \mathrm{C}$ for $15 \mathrm{sec}$; and $60^{\circ} \mathrm{C}$ for $1 \mathrm{~min}$. U6 and glyceraldehyde 3-phosphate dehydrogenase were used as reference genes for miR-610 and MDM2 mRNA expression, respectively. Each sample was analyzed in triplicate. Primers were synthesized by Guangzhou RiboBio Co., Ltd. (Guangzhou, China). Relative expression fold changes were calculated using the $2^{-\Delta \Delta C q}$ method (17).

3-(4,5-dimethylthiazol-2-yl)-2,5-diphenyltetrazolium bromide (MTT) assay. MTT assay was performed to investigate whether miR-610 had a role in glioma cell proliferation. Post-transfection with miR-610 or NC mimics and inhibitors, cells were collected and seeded in 96-well plates at 3,000 cells/well. MTT assay was performed every $24 \mathrm{~h}$ for 6 days. Briefly, $20 \mu 1$ MTT solution (Sigma-Aldrich, St. Louis, MO, USA) was added to each well and incubated for $4 \mathrm{~h}$ at $37^{\circ} \mathrm{C}$. The culture medium containing MTT solution was then removed, and $200 \mu 1$ dimethyl sulfoxide was added to each well. The absorbance was measured at $490 \mathrm{~nm}$ using an enzyme-linked immunosorbent assay reader (Bio-Rad Laboratories, Inc., Hercules, CA, USA). All experiments were analyzed in triplicate.

Cell migration and invasion assays. Migration and invasion of the human glioma cell lines were assessed using 8- $\mu \mathrm{m}$ Transwell chambers (Costar, Corning Incorporated, Corning, NY, USA). For the migration assay, $5 \times 10^{4}$ transfected cells were harvested and resuspended in $200 \mu \mathrm{l}$ serum-free RPMI 1640 medium (Gibco). The cells were placed into the upper chamber of the Transwell. RPMI 1640 containing $20 \%$ FBS $(0.5 \mathrm{ml})$ was added to the lower chamber as a chemoattractant. For the invasion assay, $5 \times 10^{4}$ transfected cells were placed into the upper chamber, which was coated with Matrigel (BD Biosciences, San Jose, CA, USA). RPMI 1640 containing 20\% FBS $(0.5 \mathrm{ml})$ was added to the lower chamber as a chemoattractant. Cells were incubated in the Transwell chambers for 12 and $24 \mathrm{~h}$ for the migration and invasion assays, respectively. The cells remaining on the upper surface of the membranes were scraped off with cotton swabs and the cells adhering to the lower surface were fixed with $100 \%$ methanol (Shanghai Macklin Biochemical Co., Ltd., Shanghai, China) for $10 \mathrm{~min}$, stained with $0.5 \%$ crystal violet (Beyotime Institute of Biotechnology, Haimen, China) and were then counted under an inverted microscope (x200; Olympus Corporation, Tokyo, Japan) to calculate their relative numbers. Each experiment was repeated at least three times.

Western blot analysis. A total of $72 \mathrm{~h}$ post-transfection, human glioma cells were washed with ice cold phosphate-buffered saline and lysed in cold radioimmunoprecipitation lysis buffer (Beyotime Institute of Biotechnology). The concentrations of the proteins were determined using a bicinchoninic acid protein assay kit (Beyotime Institute of Biotechnology). Proteins $(30 \mu \mathrm{g})$ were then separated by $10 \%$ sodium 
Table I. Correlation between miR-610 and clinicopathological features in patients with glioma.

\begin{tabular}{|c|c|c|c|c|}
\hline \multirow[b]{2}{*}{ Clinical feature } & \multirow[b]{2}{*}{$\begin{array}{l}\text { No. } \\
\text { cases }\end{array}$} & \multicolumn{2}{|c|}{ miR-610 level } & \multirow[b]{2}{*}{ P-value } \\
\hline & & $\begin{array}{c}\text { Low } \\
(n=39)\end{array}$ & $\begin{array}{l}\text { High } \\
(n=22)\end{array}$ & \\
\hline Gender & & & & 0.791 \\
\hline Male & 34 & 21 & 13 & \\
\hline Female & 27 & 18 & 9 & \\
\hline Age (years) & & & & 0.282 \\
\hline$<55$ & 26 & 19 & 7 & \\
\hline$\geq 55$ & 35 & 20 & 15 & \\
\hline Extension of resection & & & & 0.588 \\
\hline Subtotal & 22 & 13 & 9 & \\
\hline Total & 39 & 26 & 13 & \\
\hline KPS & & & & 0.014 \\
\hline$\geq 80$ & 25 & 11 & 14 & \\
\hline$<80$ & 36 & 28 & 8 & \\
\hline WHO grade & & & & 0.004 \\
\hline I-II & 29 & 13 & 16 & \\
\hline III & 32 & 26 & 6 & \\
\hline
\end{tabular}

miR, microRNA; WHO, World Health Organization; KPS, Karnofsky performance status.

dodecyl sulfate-polyacrylamide gel electrophoresis and were transferred to a polyvinylidene difluoride membranes (Beyotime Institute of Biotechnology). After blocking with 5\% skimmed milk in TBS/0.1\% Tween (TBST; Beyotime Institute of Biotechnology) at room temperature for $2 \mathrm{~h}$, the membranes were incubated with primary antibodies, including mouse anti-human MDM2 monoclonal antibody (1:1,000 dilution; cat no. ab3110) and mouse anti-human $\beta$-actin monoclonal antibody (1:1,000 dilution; cat no. ab6276; both AbCam, Cambridge, MA, USA), at $4^{\circ} \mathrm{C}$ for overnight. The PVDF membranes were washed and then incubated for $1 \mathrm{~h}$ with the corresponding horseradish peroxidase-conjugated secondary antibody in TBST. The secondary antibody used was goat anti-mouse horseradish peroxidase conjugated secondary antibody (1:5,000 dilution; ab6789; AbCam). Finally, protein bands were visualized with an enhanced chemiluminescence kit (Pierce Biotechnology, Inc., Rockford, IL, USA) and analyzed using Quantity One software (version 4.62; Bio-Rad Laboratories, Inc.).

Luciferase assay. The human glioma cells, seeded in a 12-well plate at $\sim 90 \%$ confluence, were transfected with the reporter plasmid, and miR-610 mimics or NC using Lipofectamine 2000. Renilla and firefly luciferase activity was measured using the Dual-Luciferase Reporter Assay system (Promega Corporation) and a luminometer (Tecan Group Ltd., Männedorf, Switzerland) $48 \mathrm{~h}$ post-transfection. The firefly luciferase activity was normalized to the Renilla luciferase activity for each transfected well. All the experiments were performed in triplicate.

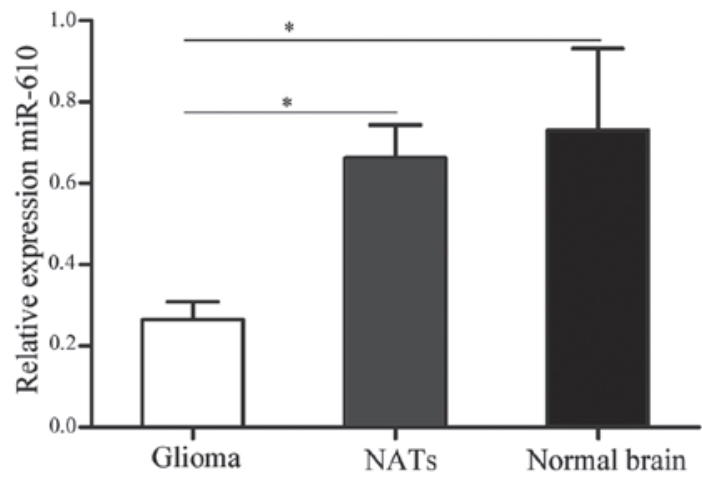

Figure 1. miR-610 levels are downregulated in glioma. The expression levels of miR-610 were significantly reduced in glioma tissues compared with matched NATs and normal brain tissues. Data are presented as the mean \pm standard deviation. ${ }^{*} \mathrm{P}<0.05$. miR, microRNA; NATs, normal adjacent tissues.

Statistical analysis. Data are presented as the mean \pm standard deviation and compared with Student's t-test or one-way analysis of variance using Stata software version 10.0 (StataCorp LP, College Station, TX, USA). The associations between miR-610 expression levels and clinicopathological factors were analyzed using the Pearson's chi square test. $\mathrm{P}<0.05$ was considered to indicate a statistically significant difference.

\section{Results}

miR-610 expression in glioma tissues and its association with clinicopathological factors. A total of 61 glioma samples were used in the present study. cDNA from the samples was subjected to RT-qPCR analysis to determine the expression levels of miR-610. As demonstrated in Fig. 1, miR-610 was significantly downregulated in glioma tissues compared with NATs and normal brain tissues $(\mathrm{P}<0.05)$. These results indicate that miR-610 may have an important function in human glioma.

The present study also determined whether the expression levels of miR-610 were associated with gender, age, extent of resection, WHO grade and KPS of patients with glioma. The statistical analysis demonstrated that miR-610 expression was significantly associated with WHO grade and KPS of patients with glioma $(\mathrm{P}<0.05$; Table I). However, there was no correlation between miR-610 expression and the other measured clinicopathological factors (gender, age and extension of resection).

miR-610 suppresses cell proliferation in U251 and U87 glioma cells. To verify the effects of miR-610 on cell proliferation, an MTT assay was performed. As demonstrated in Fig. 2, miR-610 mimics significantly inhibited cell proliferation in $\mathrm{U} 251$ and U87 cells compared with $\mathrm{NC}(\mathrm{P}<0.05)$. Conversely, miR-610 inhibitor enhanced cell proliferation in U251 and U87 cells compared with $\mathrm{NC}$ inhibitor $(\mathrm{P}<0.05)$. These results suggest that miR-610 functions as a tumor growth suppressor in glioma.

miR-610 suppresses cell migration and invasion in U251 and U87 glioma cells. To determine the effects of miR-610 on tumor cell migration and invasion, Transwell chamber assays were conducted. As demonstrated in Fig. 3A, miR-610 mimics 

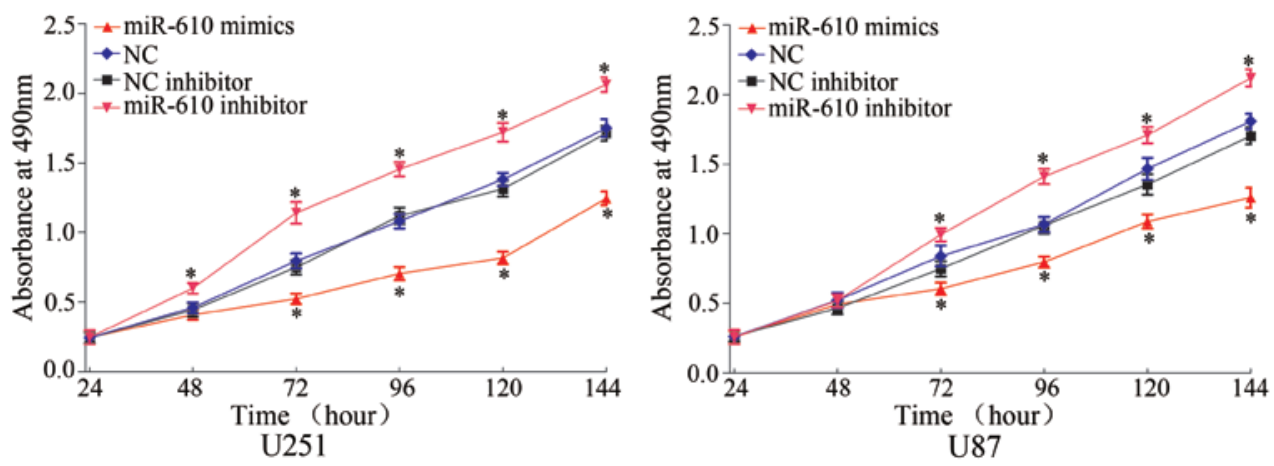

Figure 2. Effects of miR-610 on U251 and U87 cell proliferation, as determined by MTT assay. Upregulation of miR-610 significantly suppressed cell proliferation in U251 and U87 cell lines, whereas downregulation of miR-610 enhanced cell proliferation. Data are presented as the mean \pm standard deviation. "P<0.05. miR, microRNA; NC, negative control.
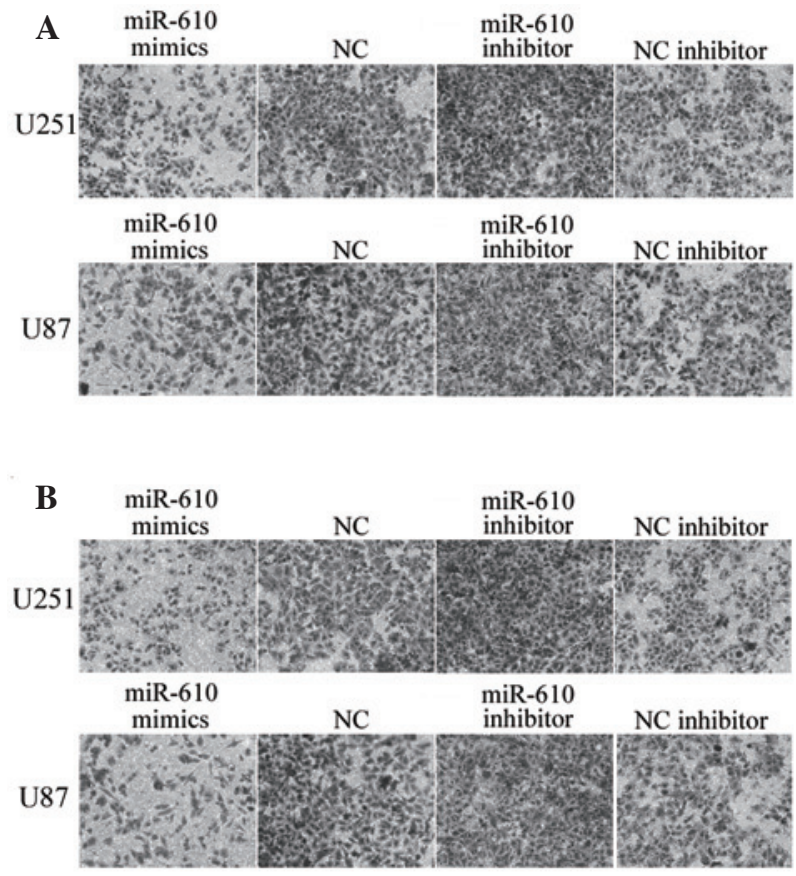
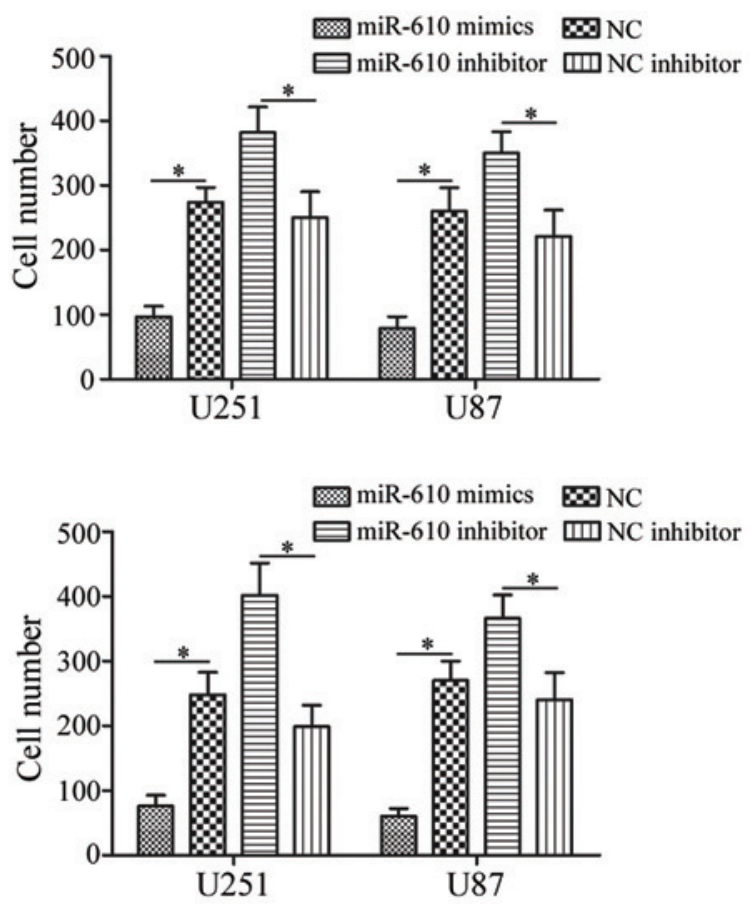

Figure 3. miR-610 inhibits cell migration and invasion in U251 and U87 cell lines. (A) miR-610 mimics inhibited U251 and U87 cell migratory abilities, whereas miR-610 inhibitor enhanced U251 and U87 cell migration. (B) The invasiveness of glioma cells transfected with miR-610 mimics was markedly decreased compared with cells transfected with NC. Downregulation of miR-610 resulted in a significant upregulation of cell invasion in U251 and U87 cells Data are presented as the mean \pm standard deviation. Magnification, $\mathrm{x} 200 .{ }^{*} \mathrm{P}<0.05$. miR, microRNA; NC, negative control.

inhibited U251 and U87 cell migration compared with NC $(\mathrm{P}<0.05)$, whereas miR-610 inhibitor increased the migration of U251 and U87 cells compared with NC inhibitor. As demonstrated by invasion assays, the invasiveness of glioma cells transfected with miR-610 mimics was significantly decreased compared with cells transfected with $\mathrm{NC}(\mathrm{P}<0.05$; Fig. 3B). However, downregulation of miR-610 induced significant U215 and U87 cell invasion compared with NC inhibitor transfected cells $(\mathrm{P}<0.05$; Fig. 3B). These results indicate that miR-610 reduces the migratory and invasive abilities of glioma cells.

MDM2 is a direct target gene of miR-610 in U251 and U87 glioma cells. To identify the targets of miR-610 in glioma, a public database (TargetScan; www.targetscan.org) was used.
MDM2 was predicted to be a target of miR-610 (Fig. 4A). To verify whether miR-610 directly targets MDM2 mRNA, luciferase reporter assays were performed. As demonstrated in Fig. 4B, miR-610 significantly inhibited the luciferase activity of MDM2 wild-type 3 '-UTR $(\mathrm{P}<0.05)$, but not MDM2 mutant 3'-UTR compared with NC in U251 and U87 cells.

RT-qPCR and western blot analysis were performed to establish whether MDM2 was downregulated at the mRNA and protein level post-transfection of U251 and U87 glioma cells with miR-610 mimics and a miR-610 inhibitor. As presented in Fig. 4C, RT-qPCR analysis demonstrated that MDM2 was significantly downregulated at the mRNA level in U251 and U87 cells post-transfection with miR-610 mimics compared with cells transfected with $\mathrm{NC}(\mathrm{P}<0.05)$. In addition, 
A

$\begin{array}{llc}\text { MDM2 3' UTR Wt } & 5^{\prime} & \text {...UUUGACUUGAAUAUGUAGCUCAU } \\ \text { hsa-miR-610 } & 3^{\prime} & \text { AGGGUCGUGUAAAUCGAGU } \\ \text { MDM2 3' UTR Mut } & 5^{\prime} & \text {...UUUGACUUGAAUAUGAUCGAGAU }\end{array}$

$\mathbf{B}$

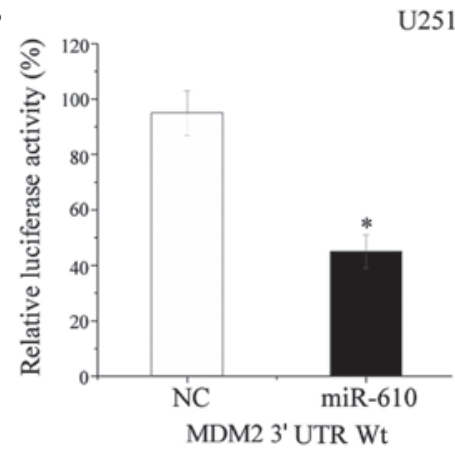

U87
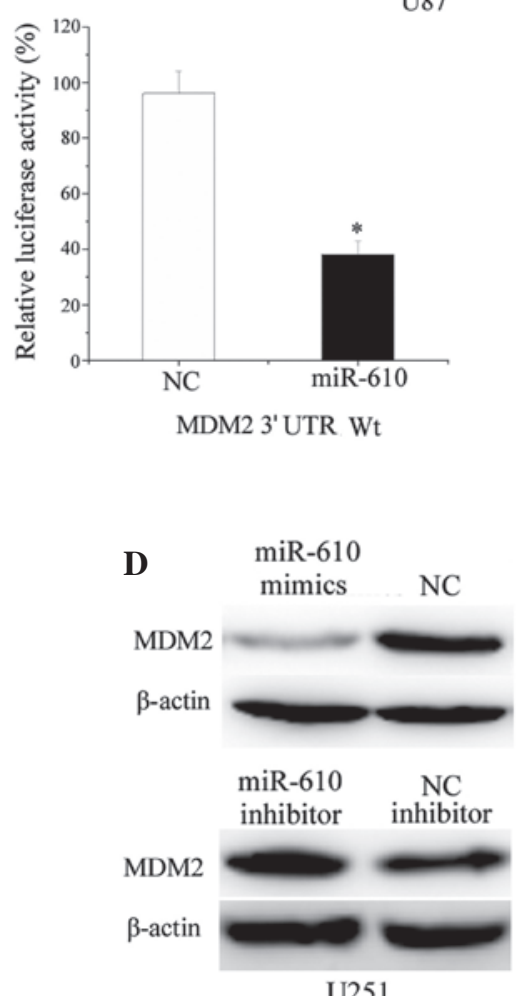
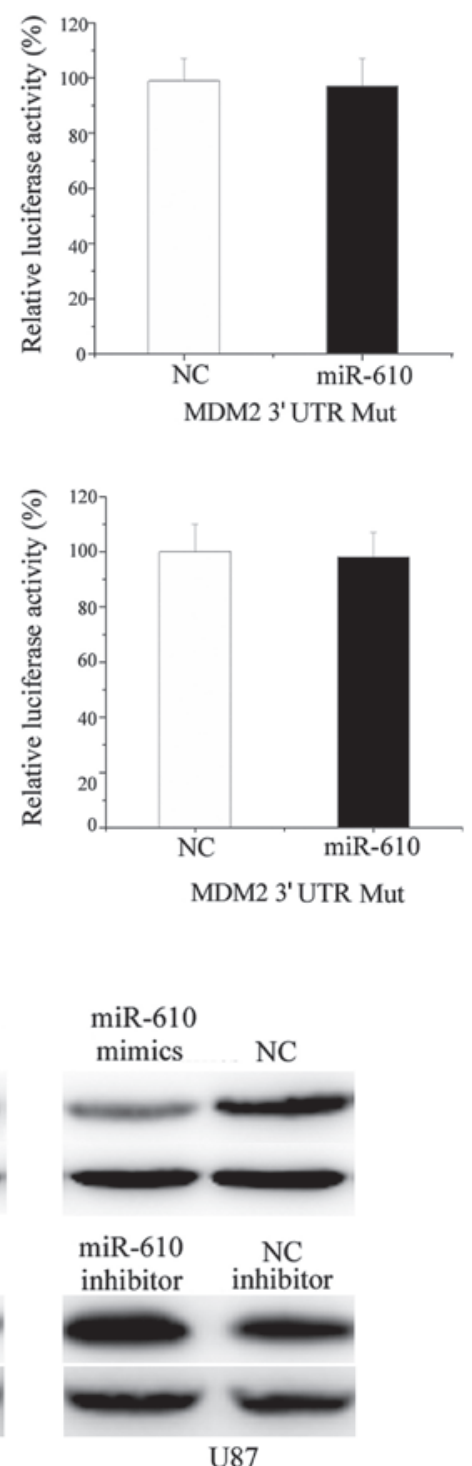

C
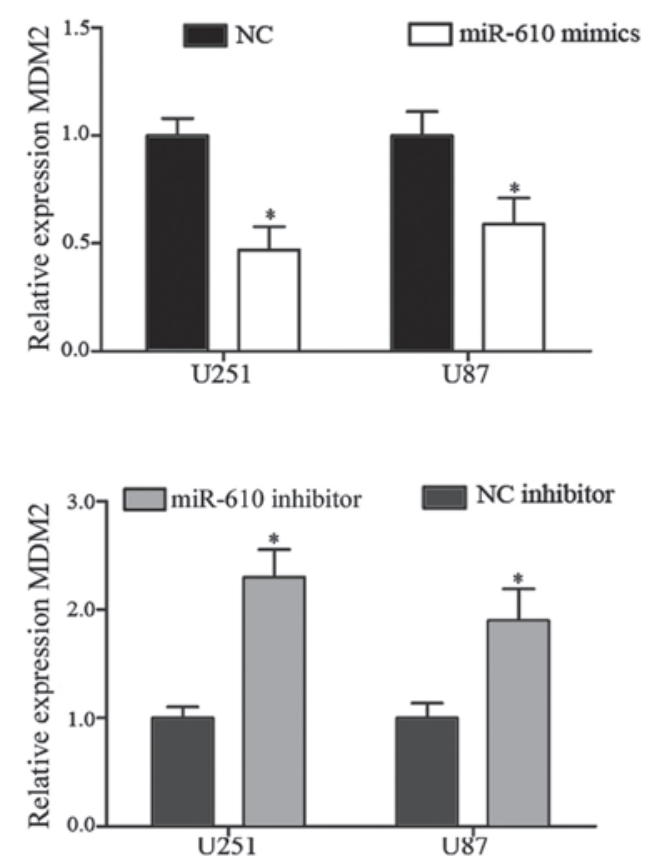

$\mathbf{E}$

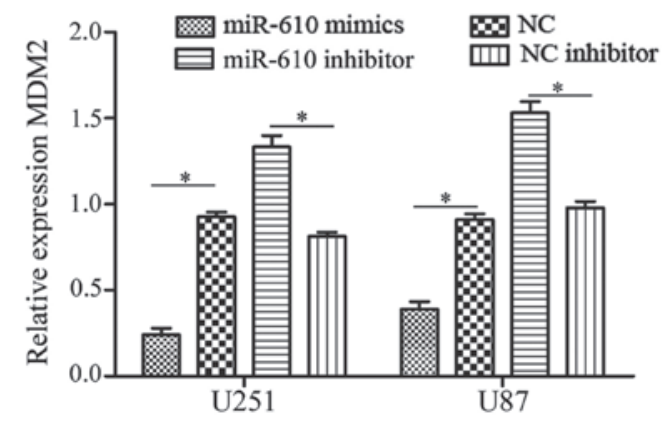

Figure 4. MDM2 is a direct target of miR-610 in vitro. (A) The miR-610 binding site in the 3'-UTR of MDM2, and the MDM2 3'-UTR Mut sequence. (B) Overexpression of miR-610 significantly inhibited MDM2 3'UTR Wt luciferase activity, but not MDM2 3'UTR Mut luciferase activity in U251 and U87 glioma cell lines " $\mathrm{P}<0.05$ vs. NC. (C) MDM2 was downregulated at the mRNA level in U251 and U87 cells following transfection with miR-610 mimics, and upregulated by miR-610 inhibitor in U251 and U87 cells. "P<0.05 vs. NC. (D) Western blot analysis and (E) relative quantification of the protein levels revealed that MDM2 was significantly downregulated in U251 and U87 cells following transfection with miR-610 mimics. miR-610 inhibitor enhanced MDM2 protein expression in $\mathrm{U} 251$ and $\mathrm{U} 87$ cells. " $\mathrm{P}<0.05$. Data are presented as the mean \pm standard deviation. MDM2, MDM2 proto-oncogene E3 ubiquitin protein ligase; 3'UTR, 3' untranslated region; Wt, wild-type; Mut, mutant; miR, microRNA; NC, negative control.

transfection with the miR-610 inhibitor significantly increased the MDM2 mRNA expression levels in U251 and U87 cells compared with the $\mathrm{NC}$ inhibitor $(\mathrm{P}<0.05)$. As demonstrated in Fig. 4D and E, compared with NC, the protein expression levels of MDM2 were significantly downregulated in U251 and U87 cells post-transfection with miR-610 mimics. Conversely, the MDM2 protein expression levels were upregulated in miR-610 inhibitor-transfected U251 and U87 cells compared with cells transfected with the $\mathrm{NC}$ inhibitor $(\mathrm{P}<0.05)$. These results suggest that MDM2 is a direct target gene of miR-610 in vitro.
miR-610 inhibits glioma cell proliferation, migration and invasion by targeting MDM2. To explore whether miR-610 inhibited glioma cell proliferation, migration and invasion by targeting MDM2, U251 and U87 cells were co-transfected with miR-610 mimics or NC, and MDM2 plasmid or control. As shown in Fig. 5A, transfection with the MDM2 plasmid significantly enhanced U251 and U87 cell proliferation, compared with the control. Furthermore, as presented in Fig. 5B and C, MDM2 plasmid significantly increased the migration and invasion of U251 and U87 compared with 


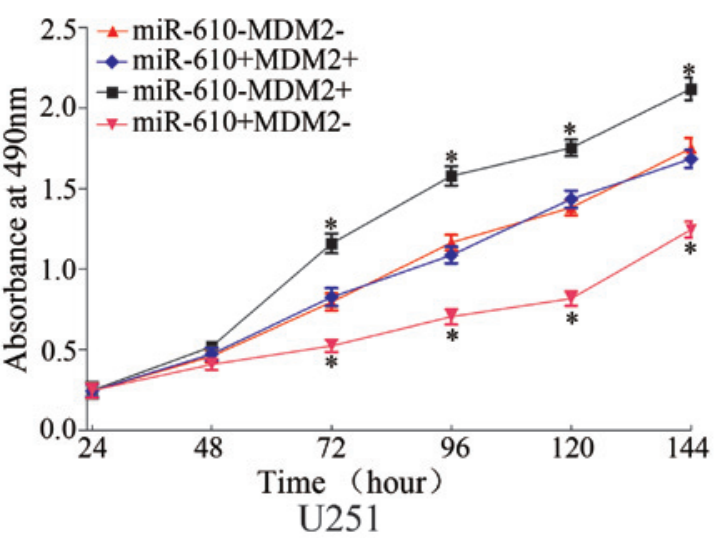

B

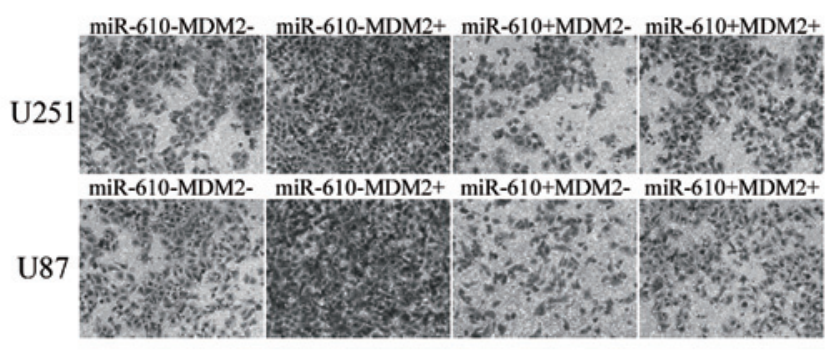

C

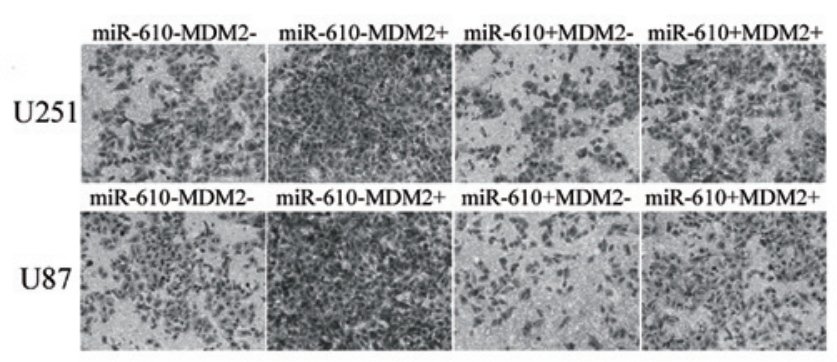

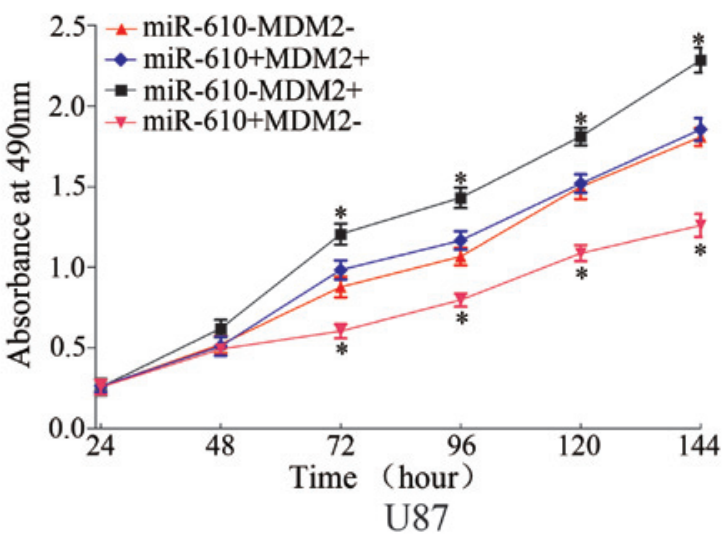
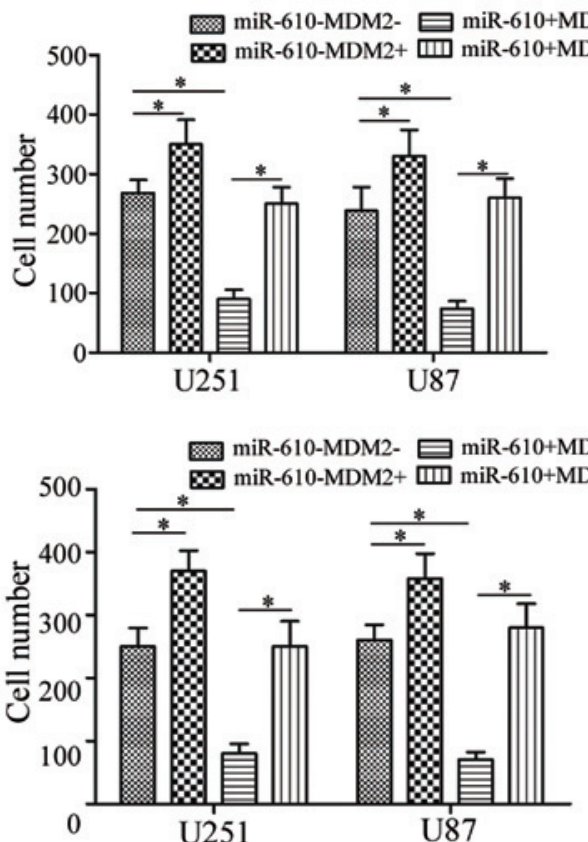

Figure 5. miR-610 inhibits glioma cell proliferation, migration and invasion by targeting MDM2. (A) MDM2 plasmid significantly increased U251 and U87 cell proliferation, and glioma cell proliferation was restored to normal levels following miR-610 overexpression and MDM2 restoration. Transfection with the MDM2 plasmid improved U251 and U87 cell (B) migration and (C) invasion. U251 and U87 cell migratory and invasive abilities were restored by miR 610 overexpression and MDM2 restoration. Data are presented as the mean \pm standard deviation. Magnification, $\mathrm{x} 200 .{ }^{*} \mathrm{P}<0.05$. miR, microRNA; MDM2, MDM2 proto-oncogene E3 ubiquitin protein ligase.

the control plasmid. These results suggest that the effects of MDM2 plasmid on the growth, migration and invasion of U251 and U87 cells were similar to those exerted by the miR-610 inhibitor, indicating that MDM2 is a functional target of miR-610 in glioma.

Rescue experiments demonstrated that, compared with miR-610 mimic-transfected cells, glioma cell proliferation, migration and invasion was restored to normal levels by co-transfection with miR-610 mimics and MDM2 plasmid $(\mathrm{P}<0.05)$. These results indicate that miR-610 regulates glioma cell proliferation, migration and invasion by targeting MDM2.

\section{Discussion}

miRNAs are important regulators of cell development, differentiation and carcinogenesis (18). The understanding of the functional importance of specific miRNAs is steadily increasing; however, it remains insufficient for numerous identified miRNAs (19). Increasing evidence indicates that miRNAs are aberrantly expressed in various types of human cancer, including human glioma; however, their function and molecular mechanisms in tumorigenesis remain unclear (20-22). The current study demonstrated that the levels of miR-610 were downregulated in human glioma and were significantly associated with WHO grade and the KPS of patients with glioma. In addition, the present study demonstrated that miR-610 suppresses the proliferation, migration and invasion of glioma cells.

Zeng et al (16) observed that miR-610 expression was downregulated in human hepatocellular carcinoma tissues and cell lines, and was correlated with hepatocellular carcinoma progression and patient survival. Furthermore, overexpression of miR-610 reduced hepatocellular carcinoma cell proliferation and $\mathrm{Wnt} / \beta$-catenin activity via directly suppressing LDL receptor related protein 6 and transducin $\beta$-like protein 1 . Wang et al (15) demonstrated that the expression levels of 
miR-610 were reduced in gastric cancer. Furthermore, miR-610 directly targeted vasodilator-stimulated phosphoprotein (VASP) and suppressed its expression, resulting in the inhibition of VASP-mediated cell migration and invasion in gastric cancer. Therefore, upregulation of miR-610 or the use of analogous pharmaceutical compounds that exogenously increase miR-610 expression may be considered effective cancer therapies for tumors caused by the activation or overexpression of these oncogenes.

To the best of our knowledge, the results of the present study provide the first evidence that miR-610 is downregulated in human glioma, which indicates that miR-610 may have a tumor suppressive function in gliomagenesis and progression. In addition, the present study demonstrated that miR-610 reduces cell proliferation, migration and invasion, also suggesting that miR-610 has a tumor suppressive function. Therefore, the results may have future clinical implications.

The present study demonstrated an important molecular association between miR-610 and MDM2. TargetScan predicted that MDM2 was a direct target gene of miR-610. It was demonstrated that MDM2 mRNA contains a miR-610 six-nucleotide seed match at position 189-195 of the MDM2 3'-UTR. In addition, a luciferase activity assay revealed that miR-610 directly targeted the MDM2 3'-UTR, as predicted by bioinformatics. Furthermore, the present study demonstrated that miR-610 negatively regulates MDM2 expression at the mRNA and protein level in glioma cell lines. Finally, transfection with the MDM2 plasmid enhanced glioma cell proliferation, migration and invasion. Rescue experiments demonstrated that glioma cell proliferation, migration and invasion were completely restored by MDM2 restoration post-transfection with miR-610 mimics. Taken together, the findings of the present study demonstrated that miR-610 is a tumor-suppressive molecule in gliomagenesis and progression.

The MDM2 gene is a proto-oncogene located on chromosome 12q13-14, which encodes a 90-kDa nuclear protein (23). MDM2 was originally isolated as an amplified sequence in a spontaneously transformed murine cell line (24). To date, the overall MDM2 gene amplification frequency is $7 \%$, with the highest frequency of amplification in soft tissue tumors $(20 \%)(25,26)$. It has previously been demonstrated to be important during tumorigenesis by transfection studies using the genomic DNA sequence (27-29). MDM2 appears to act via p53-dependent and -independent mechanisms of tumorigenesis in human tumors (26). MDM2 was previously observed to be significantly upregulated in human glioma samples compared with the control group, thus indicating that overexpression of MDM2 may be important during gliomagenesis and progression. The upregulation of MDM2 was previously demonstrated to be an early event in the malignant transformation of glioma (30). Therefore, MDM2 deserves close scrutiny as a potential target for inhibition in human glioma. The results of the present study suggested that miR-610 suppresses the proliferation, migration and invasion of glioma cells by directly targeting MDM2, indicating that miR-610 may be investigated as a targeted therapy for glioma treatment.

In conclusion, to the best of our knowledge, the present study is the first to demonstrate that miR-610 is downregulated in glioma, and associated with WHO grade and the KPS of patients with glioma. The current study also demonstrated that miR-610 suppresses cell proliferation, migration and invasion by directly targeting MDM2 in glioma cells. The identification of a target gene of miR-610 may further the understanding of the carcinogenic mechanisms of glioma. The findings of the present study indicated that miR-610 may be important as a diagnostic marker in glioma and may be exploited for the treatment of glioma. Further work is required to assess the potential of miR-610 as a treatment for glioma and other types of cancer.

\section{References}

1. Wen PY and Kesari S: Malignant gliomas in adults. N Engl J Med 359: 492-507, 2008

2. Davis FG and McCarthy BJ: Current epidemiological trends and surveillance issues in brain tumors. Expert Rev Anticancer Ther 1: 395-401, 2001.

3. Louis DN, Ohgaki H, Wiestler OD, Cavenee WK, Burger PC Jouvet A, Scheithauer BW and Kleihues P: The 2007 WHO classification of tumours of the central nervous system. Acta Neuropathol 114: 97-109, 2007.

4. Gu JJ, Gao GZ and Zhang SM: miR-218 inhibits the migration and invasion of glioma U87 cells through the Slit2-Robol pathway. Oncol Lett 9: 1561-1566, 2015.

5. Caruso C, Carcaterra M and Donato V: Role of radiotherapy for high grade gliomas management. J Neurosurg Sci 57: 163-169, 2013.

6. Schwartzbaum JA, Fisher JL, Aldape KD and Wrensch M: Epidemiology and molecular pathology of glioma. Nat Clin Pract Neurol 2: 494-503, 2006.

7. Stupp R, Mason WP, van den Bent MJ, Weller M, Fisher B, Taphoorn MJ,Belanger K, Brandes AA, Marosi C,Bogdahn U, et al; European Organisation for Research and Treatment of Cancer Brain Tumor and Radiotherapy Groups; National Cancer Institute of Canada Clinical Trials Group: Radiotherapy plus concomitant and adjuvant temozolomide for glioblastoma. N Engl J Med 352: 987-996, 2005.

8. Wang BC and Ma J: Role of microRNAs in malignant glioma. Chin Med J (Engl) 128: 1238-1244, 2015.

9. Wang LG, Ni Y, Su BH,Mu XR, Shen HCand Du JJ: MicroRNA-34b functions as a tumor suppressor and acts as a nodal point in the feedback loop with Met. Int J Oncol 42: 957-962, 2013.

10. Shen J, Niu W, Zhou M, Zhang H, Ma J, Wang L and Zhang H: MicroRNA-410 suppresses migration and invasion by targeting MDM2 in gastric cancer. PLoS One 9: e104510, 2014.

11. Kuhn AR, Schlauch K, Lao R, Halayko AJ, Gerthoffer WT and Singer CA: MicroRNA expression in human airway smooth muscle cells: Role of miR-25 in regulation of airway smooth muscle phenotype. Am J Respir Cell Mol Biol 42: 506-513, 2010.

12. Hwang HW and Mendell JT: MicroRNAs in cell proliferation, cell death, and tumorigenesis. Br J Cancer 96 (Suppl): R40-R44, 2007.

13. Calin GA, Sevignani C, Dumitru CD, Hyslop T, Noch E, Yendamuri S, Shimizu M, Rattan S, Bullrich F, Negrini M and Croce CM: Human microRNA genes are frequently located at fragile sites and genomic regions involved in cancers. Proc Natl Acad Sci USA 101: 2999-3004, 2004.

14. Mendell JT and Olson EN: MicroRNAs in stress signaling and human disease. Cell 148: 1172-1187, 2012.

15. Wang J, Zhang J, Wu J, Luo D, Su K, Shi W, Liu J, Tian Y and Wei L: MicroRNA-610 inhibits the migration and invasion of gastric cancer cells by suppressing the expression of vasodilator-stimulated phosphoprotein. Eur J Cancer 48: 1904-1913, 2012.

16. Zeng XC, Liu FQ, Yan R, Yi HM, Zhang T, Wang GY, Li Y and Jiang N: Downregulation of miR-610 promotes proliferation and tumorigenicity and activates Wnt/ $\beta$-catenin signaling in human hepatocellular carcinoma. Mol Cancer 13: 261, 2014.

17. Livak KJ and Schmittgen TD: Analysis of relative gene expression data using real-time quantitative PCR and the $2-\Delta \Delta \mathrm{Ct}$ method. Methods 25: 402-408, 2001.

18. Ichimi T, Enokida H, Okuno Y, Kunimoto R, Chiyomaru T, Kawamoto K, Kawahara K, Toki K, Kawakami K, Nishiyama $\mathrm{K}$, et al: Identification of novel microRNA targets based on microRNA signatures in bladder cancer. Int J Cancer 125: 345-352, 2009 
19. Dyrskjøt L, Ostenfeld MS, Bramsen JB, Silahtaroglu AN, Lamy P, Ramanathan R, Fristrup N, Jensen JL, Andersen CL, Zieger K, et al: Genomic profiling of microRNAs in bladder cancer: miR-129 is associated with poor outcome and promotes cell death in vitro. Cancer Res 69: 4851-4860, 2009.

20. Zhu XP, Mou KJ, Xu QF, Tang JH, Huang GH, Xu JP, Li GH, Ai SJ, Hugnot JP, Zhou Z and Lv SQ: Microarray analysis of the aberrant microRNA expression pattern in gliomas of different grades. Oncol Rep 34: 318-324, 2015.

21. Xu D, Ma P, Gao G, Gui Y, Niu X and Jin B: MicroRNA-383 expression regulates proliferation, migration, invasion, and apoptosis in human glioma cells. Tumour Biol 36: 7743-7753, 2015

22. Sun JY, Xiao WZ, Wang F, Wang YQ, Zhu YH, Wu YF, Miao ZL and Lin YC: MicroRNA-320 inhibits cell proliferation in glioma by targeting E2F1. Mol Med Rep 12: 2355-2359, 2015.

23. Nakayama T, Toguchida J, Wadayama B, Kanoe H, Kotoura $Y$ and Sasaki MS: MDM2 gene amplification in bone and soft-tissue tumors: Association with tumor progression in differentiated adipose-tissue tumors. Int J Cancer 64: 342-346, 1995.
24. Haines DS, Landers JE, Engle LJ and George DL: Physical and functional interaction between wild-type p53 and mdm2 proteins. Mol Cell Biol 14: 1171-1178, 1994.

25. Momand J, Wu HH and Dasgupta G: MDM2 - master regulator of the p53 tumor suppressor protein. Gene 242: 15-29, 2000.

26. Momand J, Jung D, Wilczynski S and Niland J: The MDM2 gene amplification database. Nucleic Acids Res 26: 3453-3459, 1998.

27. Finlay CA: The mdm-2 oncogene can overcome wild-type p53 suppression of transformed cell growth. Mol Cell Biol 13: 301-306, 1993.

28. Leach FS, Tokino T, Meltzer P, Burrell M, Oliner JD, Smith S, Hill DE, Sidransky D, Kinzler KW and Vogelstein B: p53 Mutation and MDM2 amplification in human soft tissue sarcomas. Cancer Res 53: 2231-2234, 1993.

29. Oliner JD, Kinzler KW, Meltzer PS, George DL and Vogelstein B: Amplification of a gene encoding a $\mathrm{p} 53$-associated protein in human sarcomas. Nature 358: 80-83, 1992.

30. Wang AL, Liu ZX, Li G and Zhang LW: Expression and significance of P53 protein and MDM-2 protein in human gliomas. Chin Med J (Engl) 124: 2530-2533, 2011. 